Provided for non-commercial research and education use. Not for reproduction, distribution or commercial use.

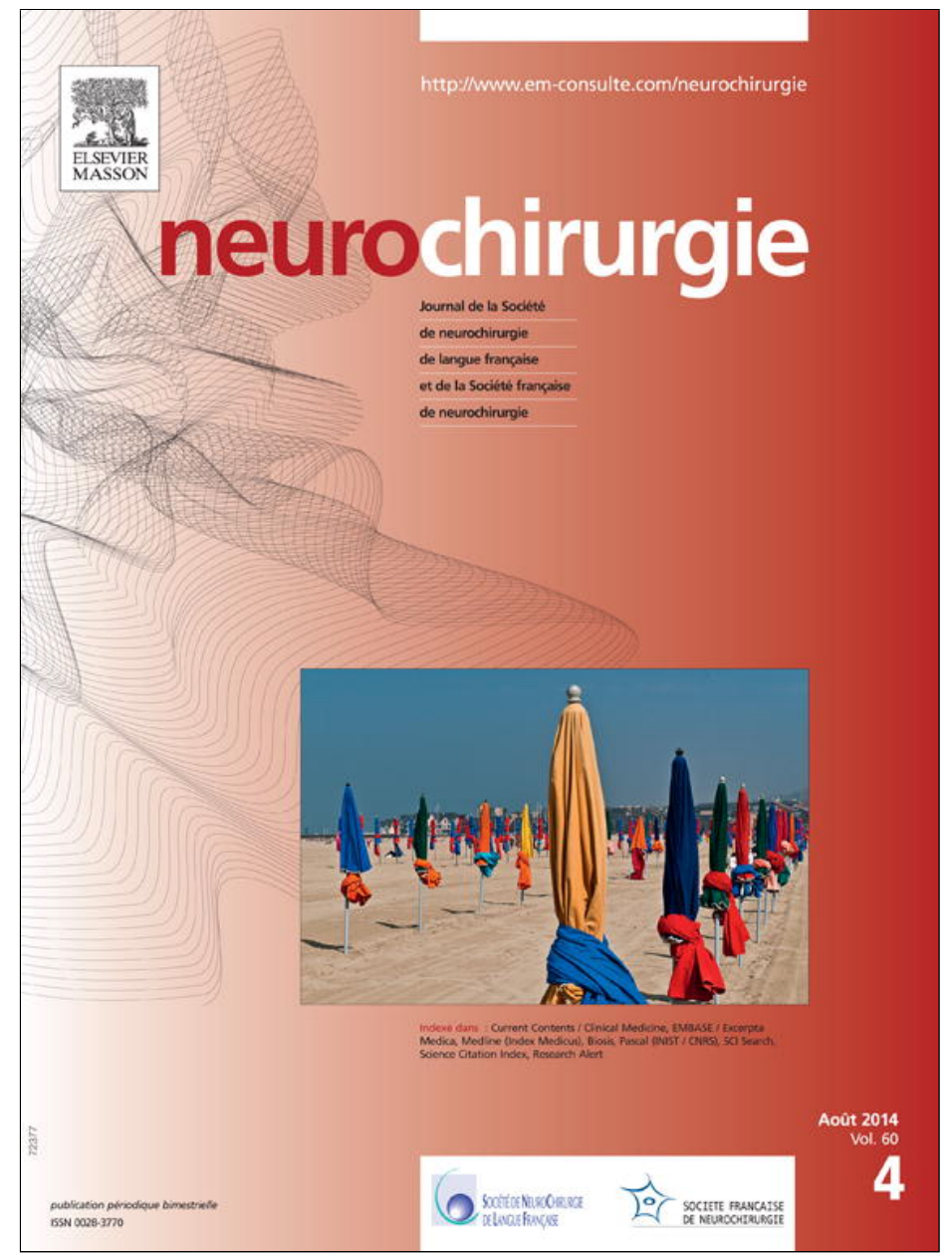

This article appeared in a journal published by Elsevier. The attached copy is furnished to the author for internal non-commercial research and education use, including for instruction at the authors institution and sharing with colleagues.

Other uses, including reproduction and distribution, or selling or licensing copies, or posting to personal, institutional or third party websites are prohibited.

In most cases authors are permitted to post their version of the article (e.g. in Word or Tex form) to their personal website or institutional repository. Authors requiring further information regarding Elsevier's archiving and manuscript policies are encouraged to visit:

http://www.elsevier.com/authorsrights 


\title{
Spinal infections due to Eikenella corrodens: Case report and literature review
}

\author{
Infections spinales à Eikenella corrodens : à propos d'un cas et résumé \\ de la littérature \\ C. Yetimoglu ${ }^{\mathrm{a}, *}$, P. Rafeiner ${ }^{\mathrm{b}}$, D. Engel ${ }^{\mathrm{a}}$, J.-Y. Fournier ${ }^{\mathrm{a}}$ \\ a Service de neurochirurgie, hôpital Cantonal de St. Gall, Rorschacher Strasse 95, 9007 St. Gall, Switzerland \\ ${ }^{\mathrm{b}}$ Clinique de medicine interne, hôpital de Zofingen, 4800 Zofingen, Switzerland
}

\section{A R T I C L E I N F O}

\section{Article history:}

Received 21 November 2012

Received in revised form 26 February 2014

Accepted 29 March 2014

Available online 27 May 2014

\section{Keywords:}

Spinal infection

Eikenella corrodens

Cervical spondylitis

Surgical site infection

\section{Mots clés}

Infection spinale

Eikenella corrodens

Spondylodiscite cervicale

Infection du site chirurgical

\begin{abstract}
A B S T R A C T
Spinal infections with Eikenella corrodens are rare. We report a unique case of infection caused by E. corrodens diagnosed more than two years after cervical surgery. All other published cases of spinal infections caused by E.corrodens were searched. Characteristics of this bacterium, its challenging diagnosis and therapy are discussed.
\end{abstract}

(C) 2014 Elsevier Masson SAS. All rights reserved.

\section{R É S U M É}

L'infection spinale à Eikenella corrodens est rare. Cet article rapporte un cas d'infection à E.corrodens survenu plus de deux ans après chirurgie cervicale. Par ailleurs, nous analysons les autres cas publiés d'infections spinales à E.corrodens. Les caractéristiques principales de ce germe sont décrites et, compte tenu des difficultés d'isolement de cette bactérie en culture standard, nous discutons les outils diagnostiques.

(c) 2014 Elsevier Masson SAS. Tous droits réservés.

\section{Introduction}

Eikenella corrodens is a ubiquitous bacterium of the oral flora. Furthermore, it colonizes the gastrointestinal and the genitourinary tract. A PubMed literature search revealed only ten cases of spinal infections caused by this bacterium (Table 1 ). Only one case of lumbar infection after surgery and one case of spontaneous cervical spondylodiscitis without prior surgery have been reported. A cervical infection with E. corrodens after a neurosurgical intervention has not been described to date.

\footnotetext{
* Corresponding author.

E-mail address: cem.yetimoglu@kssg.ch (C. Yetimoglu).
}

\section{Observation}

A 47-year-old female desk clerk was seen in our outpatient clinic with the chief complaint of cervicobrachialgia. The major cervical pain existed for half a year and was often accompanied by cephalgias and occasionally migraine and paraesthesia of the left arm. Conservative treatment remained unsuccessful. Besides, she presented a history of a car accident with cervical distortion 3 years before, a gynaecological routine intervention 30 years ago and a motorcycle accident with mild traumatic brain injury 34 years ago. Clinical examination revealed a cervical syndrome without neurological deficits. An MRI of the cervical spine showed advanced degenerative disc disease at C4/5 and C5/6 levels, as well as a cervical kyphosis, osteochondrosis, ventral spondylosis deformans and a disc herniation at C4/5 with narrowing of the spinal canal 
Table 1

Literature review of articles reporting spinal infection of Eikinella corrodens.

Revue de la littérature sur des articles rapportant une infection spinale à Eikinella corrodens.

\begin{tabular}{|c|c|c|c|c|c|c|}
\hline Name of study & Type of study & Location & Spontaneous & Postoperative & Antibiotics & Surgical revision \\
\hline Ang et al., 2002 [1] & Case report et review & L4-L5 & No & Yes & Yes & Yes \\
\hline Bridgeman et al., 1990 [2] & Case report & Lumbar & Yes & No & Yes & No \\
\hline Emmett et al., 2000 [3] & Case report & T10-T11 & Yes & No & Unknown & Unknown \\
\hline Lehman et al., 2000 [4] & Case report & $\mathrm{C} 5-\mathrm{C} 6 \mathrm{C} 6-\mathrm{C} 7$ & Yes & No & Yes & Yes \\
\hline Noordeen et al., 1992 [5] & Case report & Lumbar & Yes & No & Yes & No \\
\hline Peereboom et al., 1987 [6] & Case report & Cervical & No & Yes (transoral) & Yes & Yes \\
\hline Raab et al., 1993 [7] & Case report & L3 & Yes & No & Yes & No \\
\hline Sayana et al., 2003 [8] & Case report & L4-L5 & Yes & No & Yes & No \\
\hline Tsai et al., 2009 [9] & Case report & L4-L5 & Yes & No & Yes & Yes \\
\hline Zeitfang et al. 2002 [10] & Case report & L3-L4 & Yes & No & Yes & Yes \\
\hline
\end{tabular}

with a sagittal diameter of $8 \mathrm{~mm}$. Similar changes were observed at C5/6 with consecutive spinal stenosis with a sagittal diameter of $10 \mathrm{~mm}$.

In order to decompress the symptomatic spinal canal stenosis, an anterior discectomy C4/5 and C5/6 with interbody fusion with a tricortical autogenous iliac crest graft and anterior plating was recommended. This procedure was conducted under routine antibioprophylaxis (cefamandole $2 \mathrm{~g}$ intravenous) without any intraoperative or postoperative complications. The cervical syndrome regressed satisfactorily.

One month after the operation, at the routine postoperative assessment, the patient presented with low back pain without neurological deficits and without relevant pathologies on lumbar MRI. In addition, CT-myelography was performed and neural compression was definitively ruled out. Lumbar facet joint syndrome was diagnosed and treated with corticosteroid infiltrations.

Two years and five months after the cervical intervention, the patient was admitted at our emergency department for respiratory distress, inspiratory stridor, dysphagia and exacerbated right-sided cervicobrachial pain. The patient complained of suffering, over the past two days, from a slight progressive dysphagia since the cervical operation. During a 6-month period the patient experienced a nocturnal cervical pain (at around 4 a.m). Laboratory analysis revealed increased inflammatory parameters (C-reactive protein (CRP) $150 \mathrm{mg} / \mathrm{L}$, leucocytes $12.6 \mathrm{G} / \mathrm{L}$ ). Two blood cultures submitted for sampling were negative. Fiberoptic evaluation of the larynx did not show any typical stigmata of laryngitis. A CT scan indicated a questionable thickening of the soft tissue over the spondylodesis. An empiric intravenous therapy with clavulanic acid and amoxicillin ( $2.2 \mathrm{~g}$ three times a day) was started with the differential diagnosis of beginning bacterial laryngitis versus viral laryngitis or questionable cervical foreign body associated infection. An MRI was able to exclude an abscess and revealed a moderate enhancement of the vertebrae C3-C6 with restricted overall interpretation of this area due to the metallic plate. Clinically, the patient improved quickly; the CRP decreased to $41 \mathrm{mg} / \mathrm{L}$ within 4 days, and co-amoxicillin was switched to oral formula (625 mg t.i.d.) and discontinued 10 days after admission (CRP $19 \mathrm{mg} / \mathrm{L}$ ).

The patient was re-admitted and re-assessed 3 weeks after discontinuation of the empiric antibiotic therapy because of progressive pain during swallowing. The MRI at that time showed a reduction of the thickened soft tissue over the spondylodesis and a new intervertebral enhancement between C3 and C6 suggesting spondylodiscitis (Fig. 1A and B). Blood cultures submitted for sampling were negative. A revision operation with intraoperative sampling was suggested. Intraoperatively, the soft tissue thickening turned out to be pus. Thorough debridement with removal of the ventral plate, a C3/4 discectomy with titanium cage-augmented fusion and fresh ventral plate osteosynthesis was conducted. Samples for microbiological analysis were collected ( 1 swab of the pus for culture and for eubacterial polymerase chain reaction (PCR) and 1 intervertebral biopsy C3/4). Empiric intravenous antibiotic therapy with amoxicillin and clavulanic acid ( $2.2 \mathrm{~g}$ t.i.d.) was started again until definitive microbiological results were available after
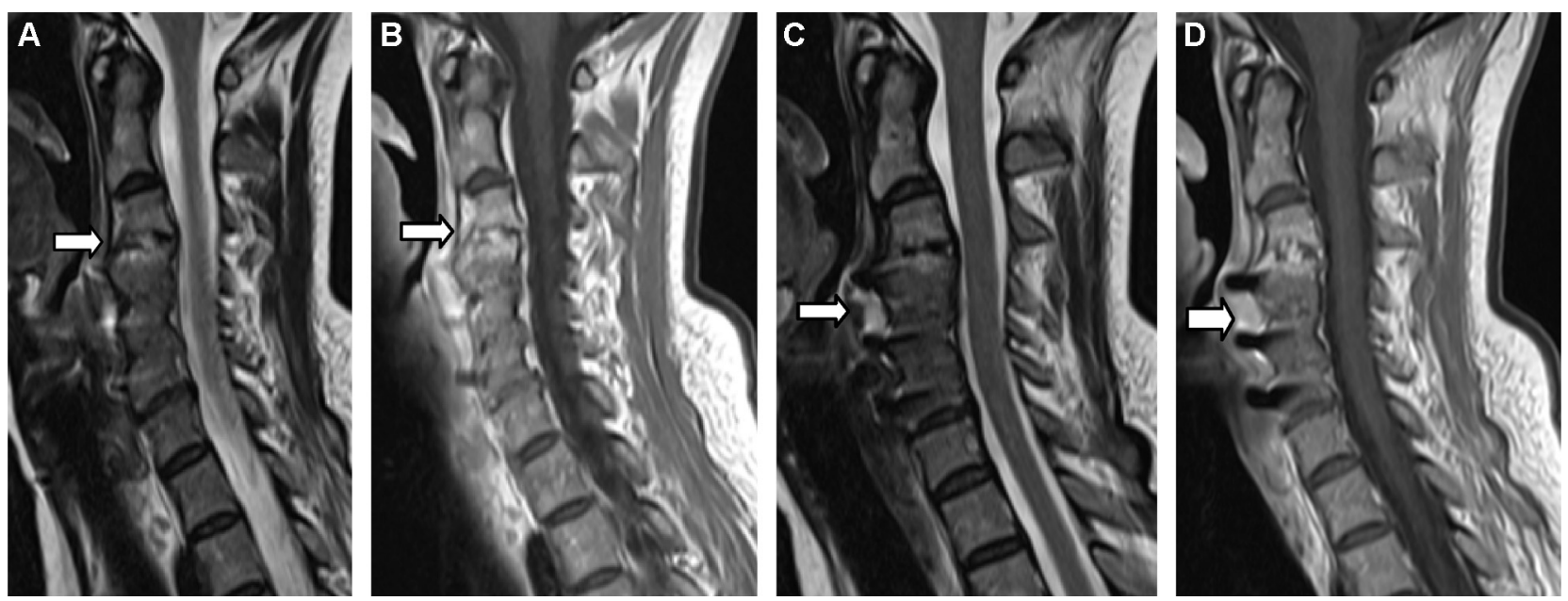

Fig. 1. A-D. MRI examination two years after spondylodesis C4-C6. T2 weighted sequences in the sagittal plane (1A) show signal intensities in the interdiscal space $\mathrm{C} 3 / \mathrm{C} 4$ with (1B) contrast enhancement in $\mathrm{T} 1$ weighted sequences with gadolinium. T2 weighted sequences in the sagittal plane (1 C) show signal intensities prevertebral at the hight of C4 with (1D) contrast enhancement in T1 weighted sequences with gadolinium, suggesting highly spondylodiscitis with a prevertebral abscess.

Examen par IRM deux ans après spondylodèse C4-C6. En séquence T2 sagittale (1A) hypersignal en regard de l'espace interdiscal C3/C4 avec (1B) prise de contraste en séquence T1 avec gadolinium. En séquence T2 sagittale (1C) hypersignal pré-vertébral en regard de C4 avec (1D) prise de contraste en séquence T1 avec gadolinium, suggérant fortement une spondylodiscite avec abcès pré-vertébral. 


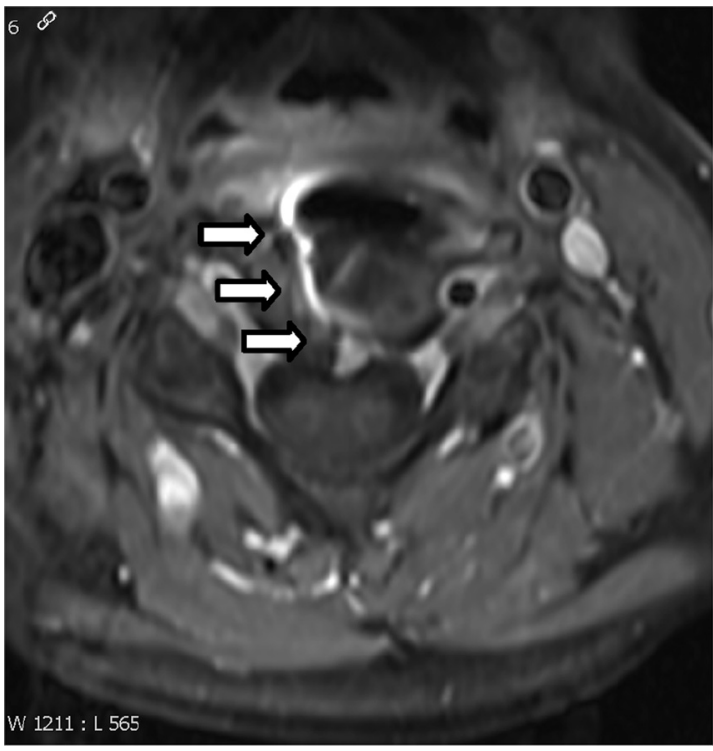

Fig. 2. T1 weighted MRI sequences with gadolinium in the axial plan show prevertebral contrast enhancement at the level of interdiscal space $\mathrm{C} 3 / 4$.

IRM séquence T1 axial avec gadolinium démontrant une prise de contraste près-vertébral au niveau de l'espace interdiscal C3/C4.

11 days. E. corrodens was identified in both microbiological cultures and by PCR. The antibiotic therapy was switched to intravenous ceftriaxone in an outpatient setting. A transthoracal echocardiography (TTE) was conducted but did not reveal any vegetation or valve dysfunction. According to the Duke's modified criteria (potential arterial embolus as 1 positive minor criterion) an endocarditis was unlikely [11]. Due to the patients' intolerance to daily injection, ceftriaxone was replaced after 6 days by ciprofloxacin orally ( $750 \mathrm{mg}$ b.i.d.), after a total of 18 days with betalactamine antibiotics. Ciprofloxacin had to be discontinued 28 days later because of a bilateral Achilles tendonitis, a common side effect of fluoroquinolones. At that time the nocturnal cervical pain and dysphagia had declined completely and inflammatory parameters had normalized. MRI images showed marginal prevertebral contrast enhancement, clear regression of prevertebral soft tissue swelling, without signs of an abscess (Fig. 2). Four weeks after discontinuation of antibiotic therapy, MRI findings remained stable (Fig. 3.). Signs and symptoms of an infection remained absent at the last follow-up 6 months after discontinuation of antibiotic therapy.

\section{Discussion}

Spinal infection due to E. corrodens is rare. In the majority of the cases this infection occurs in the lumbar spine without previous surgery. E. corrodens is a fastidious, slow-growing, facultative gramnegative rod. The pathogen primarily spread haematogenously. The entry site is classically a postulated minor mucosal lesion located in the orobuccal region. In transoral surgery the germ can also spread by continuity. The aetiology of the infection in our case remains speculative. In summary, late surgical site infections are statistically mostly caused by haematogenous spreading. Haematogenous spreading can be due to transient or persistent bacteremia. The latter situation is seen in endovascular infections i.e. in endocarditis. According to the symptoms, the inoculation of the pathogen could have occurred intraoperatively (dysphagia since the operation and nocturnal pain). According to the detected germ, haematogenous aetiology is possible as E. corrodens is not a skin germ and the oral mucosa was outside the operative site.

Ruling out endovascular affection in cases of Eikenella bacteraemia remains essential, as Eikenella is a HACEK organism (Haemophilus parainfluenzae, Aggregatibacter aphrophilus, Aggregatibacter actinomycetemcomitans, Cardiobacterium hominis, E. corrodens and Kingella kingae), a set of slow-growing gramnegative bacteria that form a normal part of the human flora and can be associated with endocarditis. HACEK organisms are known to cause false culture-negative endocarditis, especially if inoculated less than one week or if inoculated in non-enriched culture media. Modern culture media and automated blood culture systems keep the rate of false negative results rather low $[12,13]$.

Because of progressive local symptoms (nocturnal pain suggesting a status of inflammation) for at least a half a year, lack of fever and other clinical stigmata of endocarditis, and because of several negative blood cultures an acute endovascular infection was not likely (low pretest probability), according to the modified Duke's criteria proposed by Li et al. [11]. In the setting of low probability a TTE is the recommended diagnostic tool of choice [11].

The identification of $E$. corrodens can be difficult due to its often minimal intricate growth in culture. This may be one of the reasons why Eikenella is rarely identified or associated with spinal infections. The eubacterial PCR method represents a supplementary diagnostic tool in cases of fastidious growth bacteria, particularly if the diagnostic sampling is performed under empiric antibiotic therapy $[14,15]$.

The therapy of choice is rigorous debridement and antibiotic treatment. Due to the lack of data, there is no recommendation for implant associated infections by the HACEK group. In endovascular
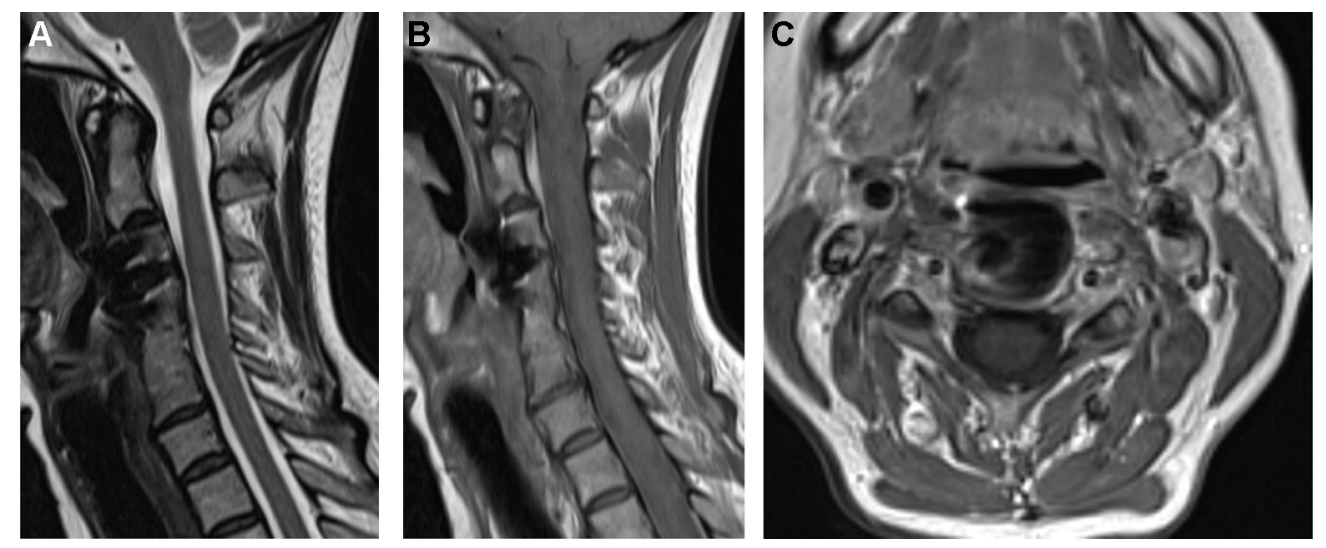

Fig. 3. A-C. In MRI examination 4 weeks after discontinuation of antibiotic therapy no more signs of discitis or prevertebral abscess in $\mathrm{T} 2$ sequences ( $3 \mathrm{~A}$ ) or $\mathrm{T} 1$ sequences with gadolinium ( $3 \mathrm{~B}$ and $3 \mathrm{C}$ ) are detectable in.

Quatre semaines après l'arrêt des antibiotiques l'examen par MRT ne montre plus de signes de discite ou d'un abcès près-vertébral en séquence T2 (3A), ni prise de contraste en séquence T1 avec gadolinium (3B et 3C). 
infections, according to the US guidelines [16], the therapy of choice is ceftriaxone or alternatively a fluoroquinolone. European guidelines for treatment of endocarditis [17] recommend ceftriaxone or the combination of ampicillin (if sensitive) and gentamycin, or, after consulting an infectious disease specialist, alternatively a fluoroquinolone. In endocarditis with a native valve, a treatment duration of 4 weeks is necessary. Regarding gram-negative bacteria, most experience in implant associated infections has been made with enterobacteriaceae and therefore (in prosthetic joint infections [18]) an intravenous betalactamine according to the in vitro susceptibilities or alternatively ciprofloxacin ( $750 \mathrm{mg}$ bid by oral route) is recommended. In cases of reimplantation of foreign material at the time of debridement, a prolonged time of antibiotic treatment might be warranted. Our original intention was a treatment of 8 to 12 weeks after reimplantation of foreign material and postulated chronic spondylitis. To our knowledge there are no systematic data to confirm this approach. Our patient was free of local and systemic symptoms after extensive debridement and an overall treatment during six and a half weeks with systemic antibiotic therapy. This stresses the importance of thorough debridement.

\section{Disclosure of interest}

The authors declare that they have no conflicts of interest concerning this article.

\section{References}

[1] Ang BS, Ngan CC. Eikenella corrodens Discitis after spinal surgery: case report and literature review. J Infect 2002;45(4):272-4.

[2] Bridgeman SA, Espley A, McCallum ME, Harper I. Eikenella corrodens osteomyelitis of the spine. J R Coll Surg Edinb 1990;35(4):263-5.

[3] Emmett L, Allman KC. Eikenella corrodens vertebral osteomyelitis. Clin Nucl Med 2000;25(12):1059-60.
[4] Lehman CR, Deckey JE, Hu SS. Eikenella corrodens vertebral osteomyelitis secondary to direct inoculation: a case report. Spine (Phila Pa 1976) 2000;25(9):1185-7

[5] Noordeen MH, Godfrey LW. Case report of an unusual cause of low back pain. Intervertebral diskitis caused by Eikenella corrodens. Clin Orthop Relat Res 1992;(280):175-8.

[6] Peereboom D, Poretz DM. Eikenella corrodens cervical osteomyelitis: case report. Va Med 1987;114(3):150-3.

[7] Raab MG, Lutz RA, Stauffer ES. Eikenella corrodens vertebral osteomyelitis. A case report and literature review. Clin Orthop Relat Res 1993;(293):144-7.

[8] Sayana MK, Chacko AJ, Mc Givney RC. Unusual cause of infective discitis in an adolescent. Postgrad Med J 2003;79(930):237-8.

[9] Tsai J, Huang TJ, Huang CC, Li YY, Hsu RW. Eikenella corrodens discitis in a habitual betel quid chewer: a case report. Spine (Phila Pa 1976) 2009;34(9):E333-6.

[10] Zeifang F, Haag M, Lill CA, Sabo D. Eikenella corrodens-induced spondylitis. Detection with 16s-RNA polymerase chain reaction. Orthopade 2002;(6):591-3.

[11] Li, et al. Proposed modifications to the Duke criteria for the diagnosis of infective endocarditis. Clin Infect Dis 2000;30(4):633-8.

[12] Baron EJ, Scott JD, Tompkins LS. Prolonged incubation and extensive subculturing do not increase recovery of clinically significant microorganisms from standard automated blood cultures. Clin Infect Dis 2005;41:1677-80.

[13] Cathy A, Petti, Hasan S, Bhally, Melvin P, Weinstein, et al. Utility of extended blood culture incubation for isolation of Haemophilus, Actinobacillus, Cardiobacterium Eikenella, and Kingella organisms: a retrospective multicenter evaluation. J Clin Microbiol 2006;44(1):257.

[14] Fuursted K, Arpi M, Lindblad BE, Pedersen LN. Broad-range PCR as a supplement to culture for detection of bacterial pathogens in patients with a clinically diagnosed spinal infection. Scand J Infect Dis 2008;40(10):772-7.

[15] Kupila L, Rantakokko-Jalava K, Jalava J, Nikkari S, Peltonen R, Meurman O, et al. Aetiological diagnosis of brain abscesses and spinal infections: application of broad range bacterial polymerase chain reaction analysis. J Neurol Neurosurg Psychiatry 2003;74(6):728-33.

[16] Baddour LM, et al. Infective endocarditis: diagnosis, antimicrobial therapy, and management of complications. Circulation 2005;111:e394-434.

[17] Habib G, et al. Guidelines on the prevention, diagnosis, and treatment of infective endocarditis (new version 2009). Eur Heart J 2009;30: 2369-413.

[18] Douglas R, Osmon, Elie F, Berbari, Anthony R, Berendt, et al. Diagnosis and management of prosthetic joint infection: clinical practice guidelines by the Infectious Diseases Society of America. Clin Infect Dis 2009;56(1): e1-25. 